\title{
VALUES, INSTITUTIONAL CULTURE AND RECOGNITION OF PRIOR LEARNING
}

\author{
A. H. M. Jacobs \\ Centre for Teaching and Learning \\ Stellenbosch University \\ Stellenbosch, South Africa \\ e-mail: jacobsa@sun.ac.za
}

\section{ABSTRACT}

In this article, I draw a link between values, institutional culture and the Stellenbosch University (SU) Regulation for Recognition of Prior Learning (RPL) and Credit Accumulation Transfer (CAT). I do this because the Regulation endorses the values of lifelong learning and the redress of inequalities. In turn, values form an important part of institutional culture. I use the "values" element of a four-part theoretical framework developed in a conceptual analytic study of institutional culture in higher education to analyse the SU Regulation for RPL and CAT. The study employed critical hermeneutics as research methodology, which exposed the hidden meanings of and revealed other ideas of "institutional culture". My analysis confirms a gap between the intentions of RPL and the way in which it plays out in practice. There is little evidence of significant strategies to address the challenges of RPL. Values related to RPL need to find expression in concrete strategies; otherwise, RPL will remain a challenging process. My analysis highlights the important role of institutional culture in RPL and CAT. Cultural systems (including institutional culture) shape the nature of practice concerning and attitudes towards RPL.

Keywords: values, higher education, policy, institutional culture, RPL, CAT

\section{INTRODUCTION}

As part of my job as higher education advisor at the Stellenbosch University (SU) Centre for Teaching and Learning, I was tasked in 2015 to look into the process of Assessment and Recognition of Prior Learning (ARPL) at the University. The task brief at the time was to write up suggestions for an implementation plan for the ARPL Policy (as it was previously called) at SU because there was a sense that reporting procedures and communication within faculties as well as between faculties and the institution centrally were not efficient. There was also no central structure to take responsibility for external queries related to ARPL. This meant, amongst others, having to study the SU ARPL Policy as well as literature on the topic of the recognition of prior learning (RPL) in higher education. The suggestions that followed were considered by the SU Committee for Teaching and Learning, and it was recommended that a task team be established to take this conversation further and to start working on the revision 
of the SU ARPL Policy, which was up for revision in 2017.

Revisions of the SU ARPL Policy (2011) were recently (June 2017) approved by the SU Council. It is now known as the SU Regulation for the Recognition of Prior Learning (RPL) and Credit Accumulation Transfer (CAT). The difference between a policy and a regulation is that a policy document is written primarily on the level of principles and contains detailed information with regard to a specific matter. Policy documents are finalised and prescriptive, and compliance is compulsory. A regulation, in contrast, is a management document and contains details, often with reference to one or more policy document. Regulations are prescriptive and compliance is compulsory (SU 2012, 3). The SU Regulation for RPL and CAT (2017, 3) translates the Policies on the Recognition of Prior Learning, Credit Accumulation and Transfer, and Assessment in Higher Education (CHE 2016) to the context of SU.

During my readings, I came across a thought-provoking notion from research done by Prinsloo (2009), who investigated RPL policies and practices in two public further education and training colleges. He found that there was little evidence of policy intentions of access and redress (constitutional values) reflected in RPL practices (Prinsloo 2009, 9). This finding and its reference to "values" took me back to my doctoral research (Jacobs 2012), which entailed a conceptual analysis of institutional culture in higher education. The reasons are two-fold. Firstly, "values" form an important part of institutional culture. Secondly, RPL needs to find a home within the university context (Sutherland 2006, 250) and, might I add, within the institutional culture of universities.

In the conceptual analysis of institutional culture, I developed a theoretical framework for analysing institutional documents. Working with a large set of constitutive meanings can be a difficult task. That is when a theoretical framework becomes useful. What makes analysing a large set of constitutive meanings so problematic is that no researcher can investigate a problem from a multitude of perspectives simultaneously. What is needed to make the task easier is a framework to help establish a vantage point, a perspective or a set of lenses through which to view the research problem. Herein lies the principal usefulness of a theoretical framework. It has great potential as a clarifying step in the research process. It enhances the focus, which leads to more clarity of the research problem (Cline 2011). Similarly, Harvey $(1990,29)$ posits that while one might be confronted by a large list of concepts in practice, it is not necessary to attempt a separate critical analysis of each and every concept, because these concepts are interrelated.

The theoretical framework was employed to investigate how institutional culture was organised, constructed and articulated in the institutional documents of two Western Cape universities, one being SU. Critical hermeneutics was employed as the research methodology 
to construct constitutive meanings of institutional culture, based on a literature review. The literature review revealed a large set of constitutive meanings that was narrowed down to the four most frequently recurring meanings, namely (1) shared values and beliefs; (2) language; (3) symbols; and (4) knowledge production. These meanings formed the theoretical framework that was used to guide the process of analysing the institutional documents. This means that the theoretical framework steered the research in terms of explaining how institutional culture was unpacked and explained in the institutional documents of the universities under study. In this article, I shall use the element of "values" of this theoretical framework to analyse the SU Regulation for RPL and CAT.

Before further unpacking the usefulness of a theoretical framework, let me briefly explain what is meant by "research methodology" and "critical hermeneutics"; the latter being the research methodology employed in the research on institutional culture (Jacobs 2012). Harvey (1990) describes research methodology as the "interface between methodical practice, substantive theory and epistemological underpinnings". Methodology is thus "the point at which method, theory and epistemology” come together in the process of investigating specific problems encountered in the social world. In grounding empirical enquiry, methodology therefore reveals the presupposed ideas that inform the knowledge generated by the inquiry (Harvey 1990, 1-2). In my opinion methodology can be regarded as a broad framework or paradigm, informed by theory, to study a social problem. The research methodology employed in the larger study to construct constitutive meanings of "institutional culture", was critical hermeneutics. Critical hermeneutics draws on two theories, namely hermeneutics and critical theory. Hermeneutics is simply defined as textual interpretation or finding meaning in the hidden word (Byrne 2001, 968). It is a suitable methodology for exposing the hidden meanings of institutional culture in institutional texts. Critical theory, on the other hand, is an emancipatory approach to dig beneath the surface of social life and uncover those assumptions that prevent us from fully understanding how the world works (Marcuse, in Waghid 2004). Thus, according to critical hermeneutics, the meaning noted on the surface makes up the periphery of much deeper layers of meaning. Critical hermeneutics provides a methodology for in depth interpretation of institutional or university texts related to institutional culture, considering the historical backgrounds of institutions. In this way it seeks for meaning far deeper than the text, and facilitating critical thoughts about institutional culture.

One of the findings of my scrutiny of institutional documents was that for "shared values and beliefs", SU is committed to creating an institutional culture that honours the values of the Constitution. Herein lies the thought provocation previously referred to. Is this conformation to the "values" element of the theoretical framework also true for the SU Regulation for RPL and 
CAT (SU 2017), which came after the timeframe covered by my doctoral research? Further justification for my link to institutional culture is found in the final report of the Ministerial Task Team for a National Strategy for the RPL (DHET 2013, 94). The report states that cultural systems (and here I include institutional culture) shape the nature of practice concerning and attitudes towards RPL.

Prinsloo $(2009,12)$ also found that the social justice intention of transformative policy was not being reflected in practice. Following this, I would like to add a second thoughtprovoking notion, one that had a strong presence in my doctoral research, namely transformation. Similar to Prinsloo, I found that there was not enough engagement with the challenges of transformation in the institutional documents that were analysed. It would therefore be interesting to find out what the SU Regulation for RPL and CAT reveals in terms of transformation.

The purpose of this article is to analyse the SU Regulation for RPL and CAT to determine how the "values" element of the theoretical framework (constructed in previous research) is articulated and also the extent to which the Regulation deals with transformation, if any.

The article will unfold as follows: firstly, I discuss "values" as constitutive meaning of institutional culture and I provide some background to the process of RPL. I use these discussions as basis for the analysis of the SU Regulation for RPL and CAT. Next, I reveal the findings of the analysis, and I discuss the findings. Before concluding the article, I briefly explain why my analysis is useful for higher education policy development.

\section{"VALUES" AS CONSTITUTIVE MEANING OF INSTITUTIONAL CULTURE}

Element number one of the theoretical framework is "shared values and beliefs" (Jacobs 2012, 94). This dimension of institutional culture is subjective. All institutions have characteristic sets of basic values and beliefs (also called moral codes), with which most of their members identify. These form the mental pictures of how they experience their institutions in reality and form the basis of distinguishing between what is right or wrong at the particular institution (Shukla 2011). No wonder then that in the literature review on institutional culture, the words "value" and "belief" occur several times. This shows they have an important role to play as building blocks of institutional culture, exemplified by the manner in which they guide the behaviour of all role players in institutions of higher education. Furthermore, it provides a frame of reference with which to interpret and analyse the meaning of events and actions as they unfold both on and off campus (Association for the Study of Higher Education [ASHE] 2005, 39); it places the focus on institutional energies geared towards certain actions while discouraging other patterns of behaviour. As such, values and beliefs form the "substance of institutional culture” (ibid 56). 
According to Sackmann (ASHE 2005), the substance of institutional culture include the following: the way things are commonly described ("what exists"), the way things commonly unfold in practice ("how things are done"), suggestions for doing things with a view to improvement ("how things should be done") and giving reasons and explanations for an event ("why things are done the way they are”). In higher education, the ideal of community ("how things should be done”), is regarded as one of the most prominent ways of promoting a sense of institutional identification. It is also a common value or belief in higher education. Building community involves focussing on and advocating the values that mark a strong institutional culture. The notion of community can improve the lives of the university community and, ultimately, the institution itself.

Another important observation for building community is that membership at universities changes all the time (ASHE 2005, 58). These changes happen because of new students and graduates, new employees, recent departures and retirements. Because of this fluidity, it is important for universities to work at building a community, and could be important for maintaining their values and beliefs. Working hard at building a community is also important for strengthening connections with former students and building active alumni.

In considering the values and beliefs that constitute institutional culture, it should be borne in mind that some groups, particularly previously marginalised groups, might not identify with all the elements of the dominant culture or regard themselves as fully integrated into the overall university community. Some of the forms that represent institutional values and beliefs (such as language and symbols) may even tend to exclude certain groups. For example, the widespread use of one particular language on campus might make some students who speak a different language feel excluded. Institutional culture can therefore exclude certain groups, even when the intention is inclusivity. This confirms the point made by Sporn $(1996,55)$, who describes how institutional cultures can be either alienating or accommodating. This means that it is crucial for universities to consider the perspectives of all role players on campus (including subgroups); otherwise, the institutional culture and the ideal of community building might be compromised.

Considering the perspectives of everyone on campus is no easy task and can be linked to the notion of social justice. Fraser (2008) views social justice as requiring social arrangements that make it possible for all to participate on an equal footing in social life. She calls it “participatory parity”, whereby everybody participates as peers. This can be facilitated within a transformative framework whereby underlying, existing structures are challenged in an effort to reshape patterns of advantage and disadvantage. According to Koopman (2017), a useful way for university communities to challenge exiting structures is to initiate conversations and share 
ideas about how a socially just university can be co-created.

In the ever-changing world of higher education and within the increasing call for social justice, universities should build institutional communities that articulate the values and beliefs of a strong institutional culture. In doing so, the functioning of universities can be improved. Applied to the context of the SU Regulation for RPL and CAT, it would mean creating an institutional culture which reflects the constitutional values of especially access and redress. Osman and Castle (in Frick, Bitzer and Leibowitz 2007, 642) caution that RPL as a mere policy without an institutional culture that incorporates RPL will not realise its true potential, in which case the institution runs the risk of RPL being regarded as a marginalised endeavour.

\section{RECOGNITION OF PRIOR LEARNING AND ITS INCREASED IMPORTANCE}

For an explanation of why RPL exists in the South African context, the National Policy for the Implementation of RPL provides a useful layout. The idea of RPL is aligned to the dominant elements of the South African higher education national policy discourse since the demise of apartheid in 1994, namely transformation, accreditation and lifelong learning. RPL is described as "a process through which non-formal learning and informal learning are measured, mediated for recognition across different contexts and certified against the requirements for credit, access, inclusion or advancement in the formal education and training system, or workplace” (SAQA $2013,5)$. The aim is to make it possible to obtain formal recognition for knowledge gained throughout life, such as in workplaces or other similar experiences. The RPL process also entails providing support to a candidate to ensure that knowledge is gained and demonstrated in terms of a relevant qualification registered on the National Qualifications Framework (NQF) (SAQA 2014).

In many readings and higher education policy documents related to the recognition of prior learning, the terms "RPL", "CAT" and "assessment" are used in a seemingly interchangeable fashion. This creates confusion, especially for the novice in the field of RPL. Let me clarify. As mentioned previously, RPL is the process through which non-formal learning and informal learning are taken into account for credit, access, inclusion or advancement in the formal education and training system. CAT refers to the "arrangement whereby the diverse features of both credit accumulations and credit transfer are combined to facilitate lifelong learning” (SAQA 2013, 4). Assessment refers to the systematic evaluation of a student's ability to demonstrate the achievement of the learning goals intended in a curriculum development (CHE 2016, 2). When RPL is linked to assessment, it is referred to as “ARPL”. RPL has a dual purpose: on the one hand, social justice, and on the other, access to or advancement through credit accumulation and credit transfer to opportunities for lifelong learning (DHET 2015, 12). 
RPL carries specific significance as it is central to an inclusive, democratic education and training system.

The first RPL-specific literature in South Africa was produced during the early 1990s by the Congress of South African Trade Unions, the largest labour movement in South Africa, as part of pre-election policy planning. It promoted the concept of RPL as principle to redress the inequalities of apartheid. The intention of RPL then was to create career pathways and access routes for the historically disadvantaged groups who had received inferior education during the apartheid era. RPL was therefore placed high on the list of national education priorities. This changed in the early 2000s. This period was characterised by a lull in the pursuance of RPL. Fewer institutions felt compelled to incorporate RPL into their education programmes, and funding for ongoing RPL capacity development was limited. However, since 2005, a number of institutions have begun to reconsider the value of RPL (Makole 2010, 8). As a result, RPL has attracted renewed interest. This renewal has been associated with efforts in promoting lifelong learning, both internationally and nationally. SAQA $(2002,9)$ acknowledges the role of lifelong learning in RPL, stating that as the South African education and training system matures, RPL will increasingly support the principle of lifelong learning. This will ensure that a nation's people are encouraged to develop and improve their skills continuously to meet the challenges of the $21^{\text {st }}$ century. It follows that RPL has gained prominence in the South African higher education sector in the past decade.

Proof of the increased prominence of RPL is found in the wealth of local literature available. Breier (2011) provides an outline of work done by local academics on the subject of RPL in higher education. She summarises some of the work along four broad themes: (1) literature that provides strong motivations in favour of RPL; (2) literature that adopts a more cautious approach to RPL; (3) literature that relates to implementation of RPL; and (4) literature that seeks to classify different types of RPL.

The following principles seek to create a foundation for the application of RPL within higher education (CHE 2016, 7):

- To achieve inclusion and to overcome a variety of barriers to access and success in higher education.

- $\quad$ RPL is more than a process of assessment but is rather a specialised pedagogical process that also includes "translation" of informal and nonformal bodies of knowledge into their formal and structured equivalents based on specified competencies.

- The implementation of RPL is context-specific in terms of institution, discipline, programme and level. 
The RPL process at SU is driven within the context of the SU Regulation for RPL and CAT (SU 2017). SU acknowledges the value of RPL as embodied in its purpose, namely to increase the accessibility of higher education institutions in general and the learning programmes of SU in particular. SU is doing commendable work with regard to RPL. The SU Committee for Learning and Teaching and the ARPL Forum are involved in addressing the challenges of the process of RPL. As an example, a meeting was held in September 2011 to discuss (1) ARPL in faculties; (2) challenges and ideas regarding the implementation of ARPL; and (3) issues that should be addressed during the revision of the SU ARPL Policy.

\section{ANALYSIS OF STELLENBOSCH UNIVERSITY'S REGULATION FOR RPL AND CAT}

The main aim of the SU Regulation for RPL and CAT is to provide a regulative framework for the recognition of prior learning and credit accumulation transfer at SU (SU 2017). I shall now analyse the SU Regulation for RPL and CAT in terms of the element of "values" of the theoretical framework.

Section 3 of the SU Regulation for RPL and CAT states that it is aimed at supporting SU's strategic positioning for the $21^{\text {st }}$ century, as described in the SU Institutional Intent and Strategy 2013-2018 (SU 2013, 4). Let me briefly pause to explore the SU Institutional Intent and Strategy 2013-2018, since it seems to greatly impact on the SU RPL and CAT Regulation.

Jacobs (2016, 212) in an analysis of the SU Institutional Intent and Strategy 2013-2018 document found that the SU Institutional Intent and Strategy 2013-2018 is built on the following values: excellence in everything that the University does, shared accountability (all stakeholders are jointly responsible for achieving the University's vision), empathy (promoting human dignity), innovation (thinking and acting in new and different ways) and leadership in service of others (leading with humility, responsibility and understanding) (SU 2013, 8). The significance of these value statements is that they lay a solid foundation for SU's future development. They also enable the University to become a more representative University, with a greater measure of equal empowerment and human dignity for all. There is therefore an emphasis on a university community characterised by equality.

Returning to my analysis of the SU Regulation for RPL and CAT: the emphasis on equality is extended in Section 5 of the Regulation. Point 5.2 interestingly states that, "SU endorses the fundamental values of the continuous development of individuals, lifelong learning and the redress of inequalities” (SU 2017, 5). This shows that the SU Regulation for RPL and CAT relates to the element of "values" of the theoretical framework. In my opinion, 
SU has an excellent and comprehensive base of well-prepared and well-written institutional documents, and the SU Regulation for RPL and CAT is no exception. However, I have a few concerns, which I will address in the next section.

\section{DISCUSSION OF FINDINGS}

My analysis of the SU Regulation for RPL and CAT shows that the University is committed to the values enshrined in the Constitution, especially with regard to redressing inequalities. This by implication also suggests a commitment to an institutional culture characterised by these values. This is encouraging because these are the values associated with RPL practices. However, I have two main concerns:

(1) The SU Regulation for RPL and CAT seems to seek compliance with national policy requirements; there is little evidence of significant actions or strategies to address the challenges related to the practice of RPL and CAT. Unless the values related to RPL practices find expression in concrete strategies and action plans, RPL will remain a significant challenge. RPL needs to find a home; it needs to be part of the University's institutional culture. The development of internal mechanisms for dealing with RPL requests in a rigorous and systematic manner within higher education institutions is essential to successful implementation of RPL policies. Until RPL practices are able to find a natural home within the university context, it will continue to be a marginalised phenomenon (Sutherland 2006, 250). I concur with Moodie (2010) that such compliance is the antithesis of what a university should stand for, which is to broaden the mind and to prepare students for engagement with a variety of intellectual and social issues.

(2) The confidence of the University in the commitment to values in the SU Regulation for RPL and CAT document represents, in my view, an attempt by the University to meet transformation targets. However, I am mindful of the absence of the use of the concept "transformation" in the document. There seems to be a subtle reluctance by the University to employ the concept “transformation”. The University's commitment to transformation needs to extend far deeper. I concur with Badat (2013) who argues that transformation in higher education involves much more than changing the demographics of a campus community. Speaking at the Vice-Chancellor's Mwalimu Julius Nyerere 10th Annual Lecture on Lifelong Learning at the University of the Western Cape (UWC), Badat said that transformation is about "creating institutional cultures that genuinely respect and appreciate difference and diversity”. Against the background of this argument by Badat, I am even more encouraged by a phrase from an opinion article by George Steyn, 
Chairperson of the SU Council, regarding the SU vision for transformation. According to Steyn (2014), "transformation relates to much more than staff and student statistics”. It includes, amongst others, fostering a welcoming campus culture for different people.

SU shows an active and conscious process of policy development, through its institutional documents. However, there appears to be a gap between policy and the way that it plays out in practice. I concur with Prinsloo (2009), who posits that the social justice intention of the policy is not being reflected in practice.

The following questions arise: should the University have an uncritical acceptance of the values espoused in the SU Regulation for RPL and CAT? Is it not perhaps time for the University to realise the changed culture of higher education? Is it not perhaps time for a paradigm shift? It is my argument that the University cannot afford to have an uncritical acceptance of the values espoused in the SU Regulation for RPL and CAT. I concur with Hendricks and Leibowitz (2016) that SU needs to be asking new sets of questions about the nature of society and the kind of students it wants to produce, and that these considerations should be incorporated into all policy formulations. Even though my analysis of the SU Regulation for RPL and CAT shows that the University is committed to the values enshrined in the Constitution, as well as an institutional culture characterised by these values, it is my contention that the University needs to spend more time and resources reviewing its institutional culture and values. Against the current background of our higher education system being at a crossroads in its history because of increasing calls for decolonisation and pressure to increase access and to promote equity, perhaps now is an opportune time to do so. During this fluid state of affairs, while traditionally embedded cultural elements of higher education, such as elitism (Morrow 2009, 41), is not as consolidated as before, institutional reflections could very well yield the required paradigm shift. I acknowledge that such a paradigm shift is no easy task, as Morrow $(2009,50)$ cautions, because it involves changing sets of practices together with the self-understandings that hold them in place. However, it has to happen.

\section{USEFULNESS OF ANALYSIS FOR DEVELOPMENT OF POLICY IN HIGHER EDUCATION}

I use McLaughlin's (2000, 449) explanation of the different aspects of the policy-making process to explain the usefulness of my analysis for (1) higher education policy development in general, as well (2) institutional policy development in particular. McLaughlin makes a distiction between "analysis of policy” and "analysis for policy”. Even though I mostly relied on "analysis of policy”, my analysis of the SU Regulation for RPL and CAT is also useful in 
terms of "analysis for policy". McLaughlin (2000, 449) describes how "analysis for policy" contributes to policy formulation in two ways. Firstly, it can facilitate policy advocacy, which refers to making specific policy recommendations. One of my recommendations is that the values related to RPL practices need to find expression in concrete strategies and action plans so that the process of RPL is more structured. Secondly, in the case of "analysis for policy" information is provided for the development of policy through supplying data that could, for example, assist with the clarification of concepts. Through my analysis of the SU Regulation for RPL and CAT by using the "values" element of the theoretical framework, I highlighted the important role of institutional culture in a teaching and learning activity such as RPL and CAT. Cultural systems (and here I include institutional culture) shape the nature of practice concerning and attitudes towards RPL. Bearing these two explanations in mind, my analysis also resembles “analysis for policy”.

Not only is the current analysis useful for higher education policy development, but further usefulness can be linked to it falling within the scope of educational research. According to Elliot (2006, 169), “educational” research includes the intention to realise educational values in action. It focusses on addressing practical questions and in so doing inevitably touches on evaluating the aims of education. Elaborating on this view, it is a form of enquiry aimed at formulating practical insights and judgements. Since these insights and judgements are rooted in the everyday experiences of educators, Elliot describes educational research as a form of common sense inquiry instead of a science. The analysis of the SU Regulation for RPL and CAT can be regarded as educational research for the following reasons: (1) It can be linked to research previously done, and is therefore not an analysis conducted in isolation. (2) The findings of the study could potentially provide information that can be used by higher education practitioners. (3) The findings can enhance continuous professional growth and the development of a critical outlook. I posit that these issues are relevant to education, as well as part of educational research.

\section{CONCLUSION}

Judging by SU's continuous efforts to write up visions, strategies, objectives, plans and projects to change the University and its institutional culture, the expectation follows that SU has an excellent base of well-prepared and well-written institutional documents, matched by equally excellent implementation strategies and plans. The strategic initiatives undertaken by SU to transform its institutional culture are commendable. However, there has not been sufficient engagement with the challenges related to such transformation, such as increased access to the University through the processes of RPL and CAT. Here I need to pause. Some scholars might 
argue that a complex issue such as institutional culture (values) cannot be properly analysed through document analysis alone. However, it should be kept in mind that the research methodology that I employed in the larger conceptual analytic study and on which the current analysis is based is critical hermeneutics. Critical hermeneutics made it possible for me to construct constitutive meanings of "institutional culture" through textual analysis. It furthermore assisted me to analyse the formulation of institutional culture within various university policy documents, thereby alerting me to of any forms of domination and manipulation that could exist. Furthermore, critical hermeneutics takes issue with any model of interpretation that claims to propose a definitive explanation for, or the final essence of any text (Kincheloe and McLaren 2000). It provides a methodology for critically thinking about and analysing generative themes, as in the case of this analysisof RPL and CAT. In this way, I contributed to discussions on RPL and CAT and their link with institutional culture.

\section{REFERENCES}

ASHE see Association for the Study of Higher Education.

Association for the Study of Higher Education. 2005. Understanding Institutional Culture. ASHE Higher Education Report 31(2): 39-54.

Badat, S. 2013. Higher education, transformation and lifelong learning. Paper presented at the ViceChancellor's Mwalimu Julius Nyerere 10th Annual Lecture on Lifelong Learning, University of the Western Cape, 14 October 2013. http://www.uwc.ac.za/Students/DLL/Pages/Archives.aspx (Accessed 21 August 2014).

Breier, M. 2011. South Africa: Research reflecting critically on Recognition of Prior Learning (RPL) research and practice. In Researching the Recognition of Prior Learning, ed. J. Harris, M. Breier and C. Wihak. London: Verso.

Byrne, M. 2001. Hermeneutics as a methodology for textual analysis. AORN Journal 73(5): 968-970.

CHE see Council on Higher Education.

Cline, D. 2011. Logical structure, theoretical framework. Centre for Excellence in Education, Arkansas State University. http://education.astate.edu/dcline/ (Accessed 16 August 2011).

Council on Higher Education. 2016. Policies on the Recognition of Prior Learning, Credit Accumulation and Transfer, and Assessment in Higher Education. Pretoria: CHE.

Department of Higher Education and Training. 2013. Ministerial Task Team on a National Strategy for the Recognition of Prior Learning (RPL): Final report incorporating a proposal for the national implementation strategy. Pretoria: DHET.

Department of Higher Education and Training. 2015. Draft Recognition of Prior Learning Policy. Pretoria: DHET.

DHET see Department of Higher Education and Training.

Elliot, J. 2006. Educational research as a form of democratic rationality. Journal of Philosophy of Education 40(2): 169-185.

Fraser, N. 2008. Reframing justice in a globalising world. In Adding insult to injury: Nancy Fraser debates her critics, ed. K. Olson, 273-291. London: Verso.

Frick, B. L., E. M. Bitzer and B. L. Leibowitz. 2007. Implications of variance in ARPL policy: A South African case study. South African Journal of Higher Education 21(4): 640-653. 
Harvey, L. 1990. Critical social research. London: Unwin Hyman.

Hendricks, C. and B. Leibowitz. 2016. Decolonising universities isn’t an easy process - but it has to happen. http://www.polity.org.za/article/decolonising-universities-isnt-an-easy-process-it-has-tohappen-2016-05-24 (Accessed 19 August 2017).

Jacobs, A. H. M. 2012. A critical-hermeneutical inquiry of institutional culture in higher education. DPhil dissertation, Stellenbosch University.

Jacobs, A. H. M. 2016. Using a theoretical framework of institutional culture to analyse an institutional strategy document. Education as Change 20(2): 204-220.

Kincheloe, J. L. and P. McLaren. 2000. Rethinking critical theory and qualitative research. In Handbook of qualitative research, ed. N. K. Denzin and Y.S. Lincoln, 279-314. $2^{\text {nd }}$ ed. Thousand Oaks, London and New Delhi: Sage.

Koopman, N. 2017. Reflecting on social justice at SU. News @ StellenboschUni, 3 March.

Makole, M. 2010. Understanding the recognition of prior learning in the context of organised labour: Opportunities and challenges. http://www.sadtu.org.za/docs/subs/2010/understanding_rpl.pdf (Accessed 26 July 2015).

McLaughlin, T. H. 2000. Philosophy and educational policy: Possibilities, tensions and tasks. Journal of Education Policy 15(4): 441-457.

Moodie, A. 2010. South Africa: Top university tackles transformation. University World News Africa Edition 16 August.

Morrow, W. 2009. Bounds of democracy. Epistemological access in higher education. Cape Town: HSRC Press.

Prinsloo, N. 2009. Recognition of prior learning within the public further education college sector. Master's thesis, University of the Western Cape.

Shukla, V. 2011. Key elements of organisational culture. http://www.brighthub.com/office/humanresources/articles/112151.aspx/ (Accessed 05 April 2011).

SAQA see South African Qualifications Authority.

South African Qualifications Authority. 2002. The Recognition of Prior Learning in the context of the South African National Qualifications Framework. Pretoria: SAQA.

South African Qualifications Authority. 2013. National Policy for the Implementation of the Recognition of Prior Learning. Pretoria: SAQA.

South African Qualifications Authority. 2014. What is RPL? http://www.saqa.org.za/ (Accessed 16 August 2017).

Sporn, B. 1996. Managing university culture: An analysis of the relationship between institutional culture and management approaches. Higher Education 32(1): 41-61.

Stellenbosch University. 2011. Policy for the Assessment and Recognition of Prior Learning (ARPL).

Stellenbosch University. 2012. Rules for policy and management documents.

Stellenbosch University. 2013. Institutional Intent and Strategy 2013-2018.

Stellenbosch University. 2017. Regulation for the Recognition of Prior Learning (RPL) and Credit Accumulation Transfer (CAT).

Steyn, G. 2014. Stellenbosch to stay on course. Weekend Argus 24 August.

SU see Stellenbosch University.

Sutherland, L. 2006. Challenges and opportunities for implementing Recognition of Prior Learning (RPL) Policy in higher education. DPhil dissertation, University of Zululand.

Waghid, Y. 2004. BEd Hons philosophy of education study guide. Stellenbosch: SUN Media. 